\title{
Total Body Irradiation Plus Bone Marrow Transplant
}

National Cancer Institute

\section{Source}

National Cancer Institute. Total Body Irradiation Plus Bone Marrow Transplant. NCI

Thesaurus. Code C161505.

A procedure in which total body irradiation is given along with a bone marrow transplant. 